\title{
A Refined Formula for the Allowable Soil Pressure Using Shear Wave Velocities
}

\author{
Semih S. Tezcan and Zuhal Ozdemir \\ Bogazici University, Bebek, Istanbul, Turkey
}

\begin{abstract}
Based on a variety of case histories of site investigations, including extensive bore hole data, laboratory testing and geophysical prospecting at more than 550 construction sites, an empirical formulation is proposed for the rapid determination of allowable bearing pressure of shallow foundations in soils and rocks. The proposed expression corroborates consistently with the results of the classical theory and is proven to be rapid, and reliable. Plate load tests have been also carried out at three different sites, in order to further confirm the validity of the proposed method. It consists of only two soil parameters, namely, the in situ measured shear wave velocity and the unit weight. The unit weight may be also determined with sufficient accuracy, by means of other empirical expressions proposed, using $\mathrm{P}$ or $\mathrm{S}$ - wave velocities. It is indicated that once the shear and P-wave velocities are measured in situ by an appropriate geophysical survey, the allowable bearing pressure as well as the coefficient of subgrade reaction and many other elasticity parameters may be determined rapidly and reliably.
\end{abstract}

Key words: Shear wave velocity, shallow foundations, allowable bearing pressure, dynamic technique, soils and rocks.

\section{Introduction}

Professor Schulze [1], a prominent historical figure in soil mechanics and foundation engineering in Germany, stated in 1943 that "For the determination of allowable bearing pressure, the geophysical methods, utilising seismic wave velocity measuring techniques with absolutely no disturbance of natural site conditions, may yield relatively more realistic results than those of the geotechnical methods, which are based primarily on bore hole data and laboratory testing of so-called undisturbed soil samples".

Since that time, various significant contributions have been made to solving geotechnical problems by means of geophysical prospecting. The P-wave velocities, for instance, have been used to determine the unconfined compressive strengths and modulus of elasticity of soil samples by Coates [2]. Hardin and Black [3], and also Hardin and Drnevich [4], based on extensive experimental data, established indispensable relations between the shear wave velocity, void ratio,

Corresponding author: Semih S. Tezcan, professor, research field: civil engineering. E-mail: tezokan@gmail.com. and shear rigidity of soils. Similarly, Ohkubo and Terasaki [5] supplied various expressions relating the seismic wave velocities to weight density, permeability, water content, unconfined compressive strength and modulus of elasticity.

The use of geophysical methods in soil mechanics has been extensively studied for the purpose of determining the properties of soils and rocks by Imai and Yoshimura [6], Tatham [7], Willkens et al. [8], Phillips et al. [9], Keceli [10, 11], Jongmans [12], Sully and Campanella [13], and Pyrak-Nolte et al. [14]. Imai and Yoshimura [6] proposed an empirical expression for the determination of bearing capacity $q_{f}$ and/or $q_{a}$ as

$$
\mathrm{nq}_{\mathrm{a}}=\mathrm{q}_{\mathrm{f}}=\mathrm{V}_{\mathrm{s}}^{2.4} /(1590)(\mathrm{kPa})
$$

which yields values unacceptably much higher than the classical theory as will be evident in next section. Campanella and Stewart [15], determined various soil parameters by digital signal processing, while Butcher and Powell [16], supplied practical geophysical techniques to assess various soil parameters related to ground stiffness. An empirical expression is also proposed by Abd El-Rahman [17], for the ultimate 
bearing capacity of soils, using the logarithm of shear wave velocity.

A series of guidelines have been also prepared in this respect by the Technical Committee TC 16 of IRTP, ISSMGE [18], and also by Sieffert [19]. Keceli [11], Turker [20], based on extensive case studies, supplied explicit expressions for the allowable bearing pressure, using shear wave velocity. In this paper, the earlier formula presented by Tezcan et al. [21], has been calibrated and improved with the soil data of 550 construction sites. Massarsch [22] determined deformation properties of fine-grained soils from seismic tests. As to the in situ measurement of $P$ and $S$ - wave velocities, various alternate techniques are available as outlined in detail by Stokoe and Woods [23], Tezcan et al. [24], Butcher et al. [25], Richart et al. [26], Kramer [27], Santamarina et al. [28].

\section{Theoretical Basis for the Empirical Expression}

In order to be able to arrive at a particular empirical expression for the allowable soil pressure $q_{a}-$ underneath a shallow foundation, the systematic boundary value approach used earlier by Keceli [11] will be followed. The state of stress and the related elastic parameters of a typical soil column is shown in Fig. 1. Considering a foundation depth of $D_{f}$ with a unit cross-sectional area of $\mathrm{A}=1$, the typical form of the compressive ultimate bearing capacity at the base of the foundation nothing but only as a format, may be written approximately as;

$$
\begin{gathered}
q_{f}=\gamma D_{f} \\
q_{a}=q_{f} / n=\gamma D_{f} / n
\end{gathered}
$$

where $q_{f}=$ ultimate bearing capacity at failure, $\gamma=$ unit weight of soil above the base of the foundation, $q_{a}=$ allowable bearing pressure, and $n=$ factor of safety. In order to be able to incorporate the shear wave velocity $\boldsymbol{V}_{\boldsymbol{s} \mathbf{2}}$ into the above expressions, the depth parameter $D_{f}$ will be expressed as velocity multiplied by time as;

$$
D_{f}=V_{s 2} t
$$

in which, the $\boldsymbol{V}_{\boldsymbol{s} 2}$ is purposely selected to be the shear wave velocity measured under the foundation, $t=$ is an unknown time parameter. The time parameter $t$ is introduced herein just as a dummy parameter in order to keep consistency in appropriate units. Substituting Eq. (4) into Eq. (3), yields

$$
q_{a}=\gamma V_{s 2} t / n
$$

The unknown time parameter $t$, will be determined on the basis of a calibration process. For this purpose, a typical 'hard' rock formation will be assumed to exist under the foundation, with the following parameters, as suggested earlier by Keceli [11];

$$
\begin{aligned}
& \mathrm{q}_{\mathrm{a}}=10000 \mathrm{kN} / \mathrm{m}^{2}, \mathrm{~V}_{\mathrm{s} 2}=4000 \mathrm{~m} / \mathrm{sec}, \\
& \gamma=35 \mathrm{kN} / \mathrm{m}^{3}, \mathrm{n}=1.4
\end{aligned}
$$

Substituting these numerical values into Eq. (5), we obtain $t=0.10 \mathrm{sec}$, thus;

$$
\mathrm{q}_{\mathrm{a}}=0.1 \gamma \mathrm{V}_{\mathrm{s} 2} / \mathrm{n}
$$

This is the desired empirical expression to determine the allowable bearing pressure $q_{a}$, in soils and rocks, once the average unit weight, $\gamma$, for the soil layer above the foundation and the in situ measured $V_{s 2}$ - wave velocity for the soil layer just below the foundation base are available. The unit of $\boldsymbol{V}_{\boldsymbol{s} 2}$ is in $\mathrm{m} / \mathrm{sec}$, the unit of $\gamma$ is in $\mathrm{kN} / \mathrm{m}^{3}$, then the resulting $q_{a}$ - value is in units of $k P a$. The unit weight values may be estimated using the empirical expressions;

$$
\begin{array}{ll} 
& \gamma_{\mathrm{p}}=\gamma_{0}+0.002 \mathrm{~V}_{\mathrm{p} 1} \\
\text { and } & \gamma_{\mathrm{s}}=4.3 \mathrm{~V}_{\mathrm{s} 1}^{0.25}
\end{array}
$$

as proposed earlier by Tezcan et al. [21], and by Keceli [29], respectively. The second expression is especially recommended for granular soils, for which the measured $\boldsymbol{V}_{\boldsymbol{s} \boldsymbol{}}$ values represent appropriately the degree of water content and/or porosity. The wave velocities must be in units of $\mathrm{m} / \mathrm{sec}$. The only remaining unknown parameter is the factor of safety, $n$, which is assumed to be, after a series of calibration processes, as follows:

$$
\begin{gathered}
\mathrm{n}=1.4\left(\text { for } \mathrm{V}_{\mathrm{s} 2} \geq 4000 \mathrm{~m} / \mathrm{sec}\right), \\
\mathrm{n}=4.0\left(\text { for } \mathrm{V}_{\mathrm{s} 2} \leq 750 \mathrm{~m} / \mathrm{sec}\right)
\end{gathered}
$$

The calibration process is based primarily on the reference $q_{a}$ - values determined by the conventional Terzaghi method, for all the data sets corresponding to the 550 - construction sites considered. For $\mathrm{V}_{\mathrm{s} 2}$ values greater than $750 \mathrm{~m} / \mathrm{sec}$ and smaller than 4000 


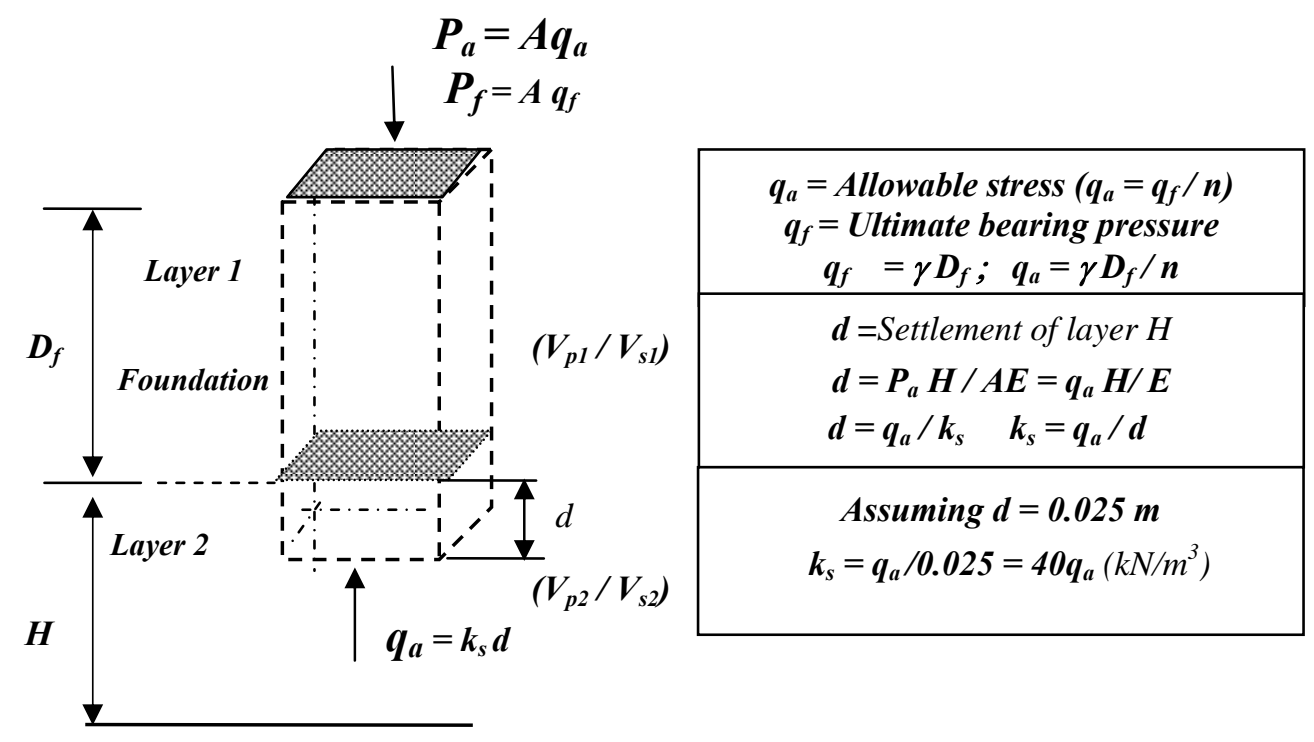

Fig. 1 Soil column and related parameters.

$\mathrm{m} / \mathrm{sec}$ a linear interpolation is recommended. The engineering rock formations are assumed to start for $\mathrm{V}_{\mathrm{s} 2}>750 \mathrm{~m} / \mathrm{sec}$. The factors of safety, as well as the empirical allowable bearing pressure expressions, for various soil (rock) types, are given in Table 1. It is seen that three distinct ranges of values are assumed for $n=$ factor of safety. For soil types with $\mathrm{V}_{\mathrm{s} 2} \leq 750$ $\mathrm{m} / \mathrm{sec}$ the factor of safety is $\mathrm{n}=4$, for rocks with $\mathrm{V}_{\mathrm{s} 2} \geq$ $4000 \mathrm{~m} / \mathrm{sec}$, it is $\mathrm{n}=1.4$. For other intermediate values of shear wave velocity, linear interpolation is recommended. The validity of these values has been extensively checked and calibrated by the soil data at 550 construction sites. The relatively higher value of factor of safety assumed for soils is deemed to be appropriate to compensate the inaccuracies and gaps existing in the measured values of shear wave velocity. In fact, Terzaghi and Peck [30] states that "The factor of safety of the foundation with respect to breaking into the ground should not be less than about 3".
It is determined by Terzaghi and Peck [30] also that the width of footing, $B$, has a reducing influence on the value of allowable bearing pressure for granular soils. Therefore, a correction factor $\beta$ is introduced into the formula, for sandy soils only, as shown in the third line of Table 1 . The proposed values of this correction factor, for different foundation width $B$, are as follows:

$$
\begin{array}{ll}
\beta=1.00 & \text { for }(0 \leq B \leq 1.20 \mathrm{~m}) \\
\beta=1.13-0.11 \mathrm{~B} & \text { for }(1.2 \leq \mathrm{B} \leq 3.00 \mathrm{~m}) \\
\beta=0.83-0.01 \mathrm{~B} & \text { for }(3.0 \leq \mathrm{B} \leq 12.0 \mathrm{~m})
\end{array}
$$

\section{Coefficient of Subgrade Reaction}

The shear wave velocity may be used successfully to determine $k_{s}=$ coefficient of subgrade reaction of the soil layer just beneath the foundation base by making use of the expressions given in Fig. 1. The coefficient of subgrade reaction $k_{s}$, is defined, similar to the definition of spring constant in engineering

Table 1 Factors of safety, $n$, for soils and rocks ${ }^{(1)}$

\begin{tabular}{|c|c|c|c|}
\hline Soil type & $\mathrm{V}_{\mathrm{s}}-$ range $(\mathrm{m} / \mathrm{sec})$ & $\mathrm{n}$ & $\mathrm{q}_{\mathrm{a}}\left(\mathrm{kN} / \mathrm{m}^{2}\right)$ \\
\hline "Hard" rocks & $\mathrm{V}_{\mathrm{s}} \geq 4000$ & $\mathrm{n}=1.4$ & $\mathrm{q}_{\mathrm{a}}=0.071 \gamma \mathrm{V}_{\mathrm{s}}$ \\
\hline "Soft" rocks & $750 \leq \mathrm{V}_{\mathrm{s}} \leq 4000$ & $\mathrm{n}=4.6-8.10^{-4} \mathrm{~V}_{\mathrm{s}}$ & $\mathrm{q}_{\mathrm{a}}=0.1 \gamma \mathrm{V}_{\mathrm{s}} / \mathrm{n}$ \\
\hline Soils & $750 \geq \mathrm{V}_{\mathrm{s}}$ & $\mathrm{n}=4.0$ & $\mathrm{q}_{\mathrm{a}}=0.025 \gamma \mathrm{V}_{\mathrm{s}} \beta$ \\
\hline
\end{tabular}

\footnotetext{
${ }^{(1)}$ Linear interpolation is applied for $750 \leq \mathrm{V}_{\mathrm{s}} \leq 4000 \mathrm{~m} / \mathrm{sec}$. $\beta$ correction factor is used for sands only (Eq. 10).
} 
mechanics, to be the necessary vertical pressure to produce a unit vertical displacement and expressed as:

$$
\mathrm{k}_{\mathrm{s}}=\mathrm{q}_{\mathrm{a}} / \mathrm{d}
$$

For shallow foundations, the total vertical displacement is restricted to 1 inch $=0.025 \mathrm{~m}$, as prescribed by Terzaghi and Peck [30]. When, $\mathrm{d}=$ $0.025 \mathrm{~m}$ is substituted in Eq. (11), the coefficient of subgrade reaction becomes in units of $\mathrm{kN} / \mathrm{m}^{3}$;

$$
\begin{aligned}
\mathrm{k}_{\mathrm{s}} & =40 \mathrm{q}_{\mathrm{a}} \\
\text { or } \mathrm{k}_{\mathrm{s}} & =4 \gamma \mathrm{V}_{\mathrm{s} 2} / \mathrm{n}
\end{aligned}
$$

\section{Elasticity Parameters}

Once, $V_{p 2}$ and $V_{s 2}$ seismic wave velocities are measured, by geophysical means, for the soil layer No.2 just under the foundation, several parameters of elasticity, such as $G=$ Shear modulus, $E_{c}=$ Constraint modulus of elasticity, $E=$ Modulus of elasticity (Young's modulus), $E_{k}=$ Bulk modulus, and $\mu=$ Poisson's ratio may be obtained easily. The Shear modulus, $G$, and the Constraint modulus, $E_{c}$, are related to the shear and $P$ - wave velocities by the following expressions, respectively;

$$
G=\rho V_{s}^{2}
$$

$$
\text { and } \quad E_{c}=\rho \boldsymbol{V}_{p}^{2}
$$

where, $\rho=$ mass density given by $\rho=\gamma / g$. From the Theory of Elasticity, it is known that, $E=$ the Young's modulus of elasticity is related to $E_{C}=$ the Constraint modulus and also to $G=$ the Shear modulus by the following expressions:

$$
\begin{gathered}
\mathrm{E}=\mathrm{E}_{\mathrm{c}}(1+\mu)(1-2 \mu) /(1-\mu) \\
\mathrm{E}=2(1+\mu) \mathrm{G}
\end{gathered}
$$

Utilising Eqs. (14) and (15) and also substituting $\alpha$, as

$$
\alpha=\mathrm{E}_{\mathrm{c}} / \mathrm{G}=\left(\mathrm{V}_{\mathrm{p}} / \mathrm{V}_{\mathrm{s}}\right)^{2}
$$

into Eqs. (16) and (17), we obtain

$$
\begin{array}{r}
\mu=(\alpha-2) / 2(\alpha-1) \\
\text { or, } \quad \alpha=(2 \mu-2) /(2 \mu-1)
\end{array}
$$

The modulus of elasticity is directly obtained from Eq. (17) as;

$$
\mathrm{E}=(3 \alpha-4) \mathrm{G} /(\alpha-1)
$$

The Constraint modulus $E_{c}$, may be also obtained in terms of $\alpha$ as ;

$$
\begin{aligned}
\mathrm{E}_{\mathrm{c}} & =\alpha(\alpha-1) \mathrm{E} /(3 \alpha-4) \\
\text { or, } \mathrm{E}_{\mathrm{c}} & =\gamma \mathrm{V}_{\mathrm{p}}{ }^{2} / \mathrm{g}
\end{aligned}
$$

The Bulk modulus $E_{k}$, of the soil layer, may be expressed, from the theory of elasticity, as

$$
\begin{gathered}
\mathrm{E}_{\mathrm{k}}=\mathrm{E} / 3(1-2 \mu) \\
\mathrm{E}_{\mathrm{k}}=(\alpha-1) \mathrm{E} / 3=\gamma\left(\boldsymbol{V}_{\boldsymbol{p}}^{2}-4 \boldsymbol{V}_{\boldsymbol{s}}^{2} / 3\right) / \mathrm{g}
\end{gathered}
$$

\section{Case Studies}

The allowable bearing pressures have been also determined at more than 550 construction sites in and around the Kocaeli and Istanbul Provinces in Turkey, between the years 2005-2010. At each construction site, by virtue of City by-law, appropriate number of bore holes were drilled, SPT counts conducted, undisturbed soil samples were taken for laboratory testing purposes, where shear strength $-c$, the internal angle of friction $-\phi$, unconfined compression strength $-q_{u}$ and unit weight $-\gamma$ were determined. Subsequently, following the classical procedure of Terzaghi and Peck [30], the ultimate capacity and also the allowable bearing pressures were determined, by assuming the factor of safety as $n=3$. For granular soils, immediate settlement calculations were also conducted, in order to determine whether the shear failure mechanism or the maximum settlement criterion would control the design.

The numerical values of the allowable bearing pressures, $q_{a}$, determined in accordance with the conventional Terzaghi theory, are shown by a triangular $(\Delta)$ symbol, in Fig. 2, where the three digit numbers refer to the data base file numbers of specific construction sites. Parallel to these classical soil investigations, the $P$ - and $S$ - wave velocities have been measured in situ, right at the foundation level for the purpose of determining the allowable bearing pressures, $q_{a}$, which are shown by means of a circle (o), in Fig. 2. Two separate linear regression lines 
were also shown in Fig. 2, for the purpose of indicating the average values of allowable bearing pressures determined by "dynamic" and "conventional" methods. In order to obtain an idea about the relative conservatism of the two methods, the ratios of allowable bearing pressures $\left(\mathrm{r}=\mathrm{q}_{\mathrm{ad}} / \mathrm{q}_{\mathrm{ac}}\right)$, as determined by the "dynamic" and "conventional" methods, have been plotted against the $V_{s}$ - values in Fig. 3.

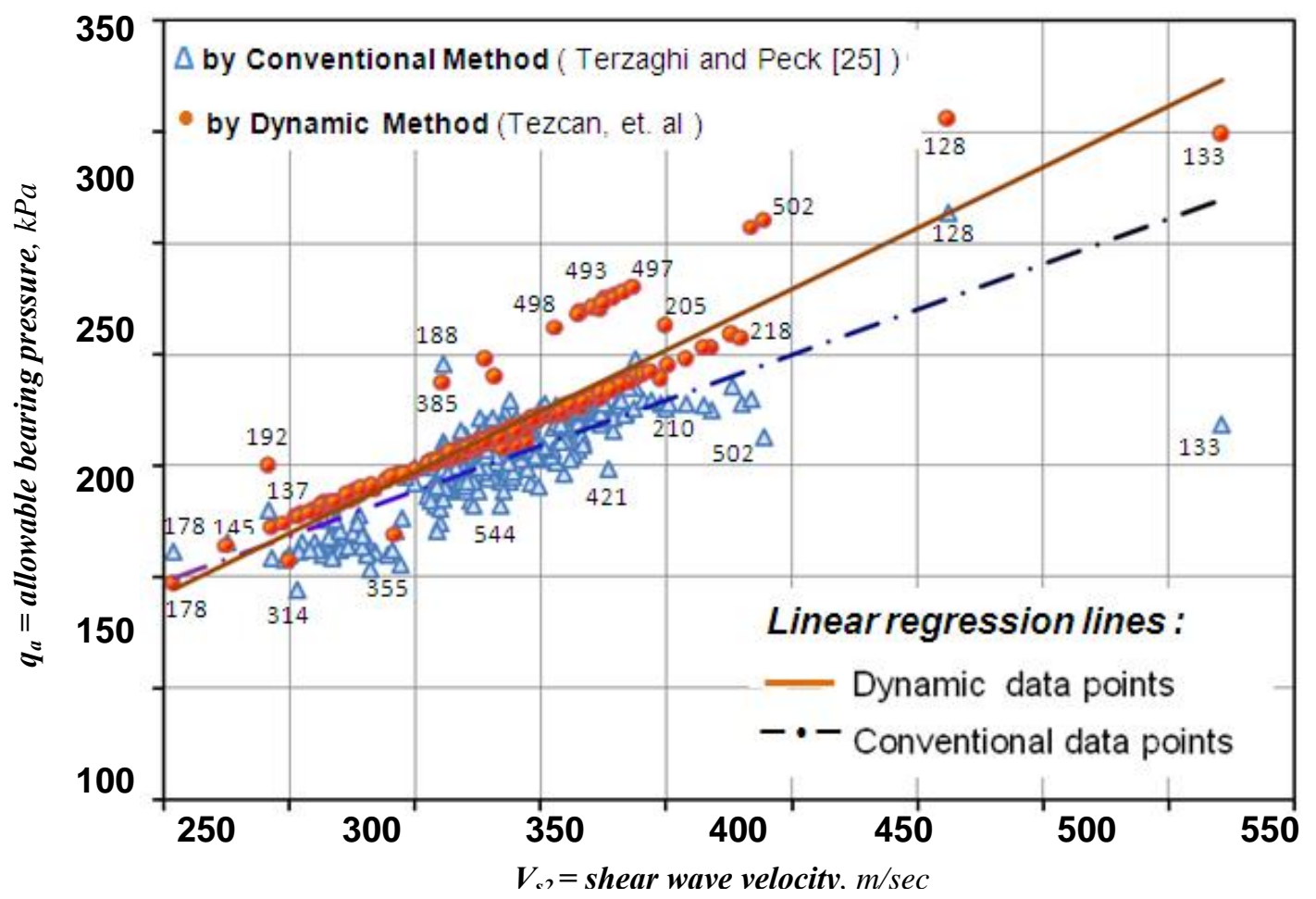

Fig. 2 Comparative results of "Conventional” and "Dynamic" methods.

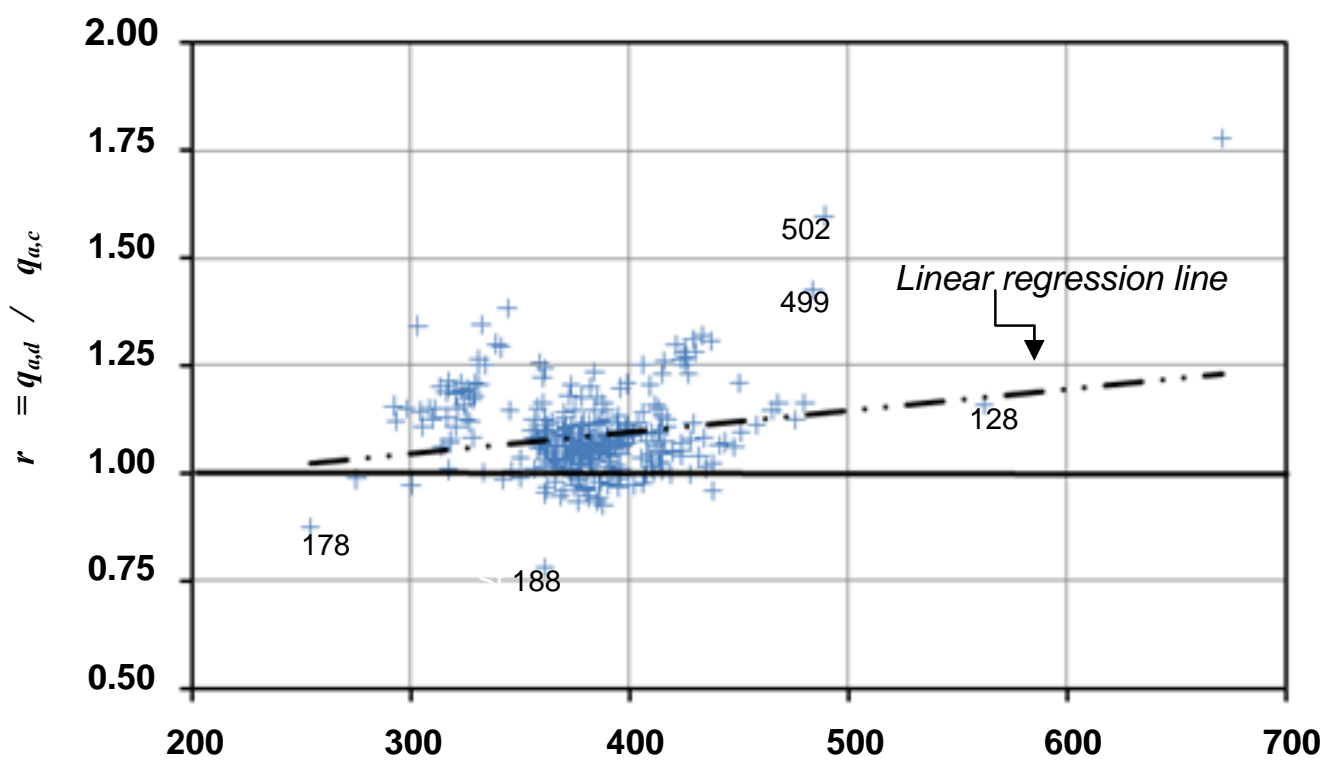

$V_{s 2}=$ shear wave velocity, $\mathrm{m} / \mathrm{sec}$

Fig. 3 Ratios of allowable bearing pressures $\left(q_{\mathrm{a}, \mathrm{d}} / \mathrm{q}_{\mathrm{a}, \mathrm{c}}\right)$ as determined by the "dynamic" and the "conventional” methods. 
It is seen that the linear regression line indicates for $V_{s}$ - values smaller than $400 \mathrm{~m} / \mathrm{sec}$ a narrow band of $\mathrm{r}$ $=1.03$ to $\mathrm{r}=1.12$, which should be regarded as quite acceptable. The "dynamic" method proposed herein yields allowable bearing pressures slightly (on the order of 3 to 10 percent) greater than those of the "conventional" method for $V_{s}$ - values smaller than $400 \mathrm{~m} / \mathrm{sec}$. In fact, the "conventional" method fails to produce reliable and consistent results for relatively strong soils and soft rocks, because it is difficult to determine the appropriate soil parameters $c$, and $\phi$ for use in the "conventional" method. At construction site Nos: 133, 134, 138, 139, 206, 207, 214, 215, 219, 502, 507 and 544, where the soil conditions have been mostly weathered andesite, granodiorite arena, greywacke, limestone, etc did not allow for the measurement of $c$ and $\phi-$ values. Therefore, the use of "dynamic" method becomes inevitable for such strong soils with $\mathrm{V}_{\mathrm{s} 2}>400 \mathrm{~m} / \mathrm{sec}$.

The list of soil parameters determined by in situ and also by laboratory testing through geotechnical prospecting, as well as the in situ measured $V_{p}$ and $V_{s}$ - velocities at each of the 550 construction sites, are too voluminous to be included herein. Those researchers interested to have access to these particular data base, may inquire from internet www.superonline.com, www.tezokan.com.

\section{Seismic Wave Velocities}

The seismic wave velocities have been measured using $P$ - and $S$ - geophones by means of a $24-$
Channel Geometrics Abem - Pasi seismic instrument, capable of noise filtering. The $P$ - waves have been generated by hitting 6 - blows vertically, with a 0.15 $k N$ hammer, onto a $250 \times 250 \times 16 \mathrm{~mm}$ size steel plate placed horizontally on ground. For the purpose of generating $S$ - waves however, an open ditch of size $1.4 \times 1.4 \times 1.4 \mathrm{~m}$ was excavated and then two steel plates were placed on opposite vertical faces of this ditch parallel to the conterline of the geophones. Using the same $0.15 \mathrm{kN}$ hammer, 6 heavy horizontal blows were applied onto each of these vertical steel plates. The necessary polarity of the $S$ - wawes was achieved by hitting these vertical steel plates horizontally in opposite directions, nonconcurrently.

\section{Plate Load Testing}

For purposes of correlating the allowable bearing pressures determined by various methods, plate loading tests have been carried out at three particular construction Sites Nos: 335, 502 and 544. The soil parameters $c, q_{u}$, and $\gamma$ as determined by laboratory testing, as well as the $P$ and $S$ - wave velocities measured at site by geophysical prospecting are all shown in Table 3. A thick steel bearing plate of 316.2 $\mathrm{mm} \times 316.2 \mathrm{~mm}=0.10$ square meter in size is used under the test platform of size $1.50 \mathrm{~m}$ by $1.50 \mathrm{~m}$. The tests are carried out right at the bottom elevations of foundations. One half of the bearing pressure $\sigma_{0}$, which produced a settlement of $\mathrm{s}=12.7 \mathrm{~mm}$ was selected as the allowable pressure $q_{a}$ as shown in Fig. 4. It is seen clearly in Table 2 that the results of the

Table 2 Comparative evaluation of allowable pressures.

\begin{tabular}{|c|c|c|c|c|c|c|c|c|c|}
\hline \multirow{4}{*}{$\begin{array}{l}\text { Site No Owner Lot Nos } \\
\text { (soil type) }\end{array}$} & \multicolumn{6}{|c|}{ Various soil parameters $(\phi=0)$} & \multicolumn{3}{|c|}{$q_{a}=$ allowable pressure } \\
\hline & $q_{u}^{(1)}$ & $D_{f}$ & $c$ & $\gamma_{l a b}$ & $V_{p 2}$ & $V_{s 2}$ & Terzaghi $^{(2)}$ & Tezcan, et.al. ${ }^{(3)}$ & Load test \\
\hline & \multirow{2}{*}{$k P a$} & \multirow[b]{2}{*}{$m$} & \multirow[b]{2}{*}{$k P a$} & \multirow{2}{*}{$k N / m^{3}$} & \multirow[b]{2}{*}{$\mathrm{m} / \mathrm{sec}$} & \multirow[b]{2}{*}{$\mathrm{m} / \mathrm{sec}$} & Eq. 26 & & Fig.4 \\
\hline & & & & & & & $k P a$ & $k P a$ & $k P a$ \\
\hline $\begin{array}{|lll|}335 & \text { Suleyman } & \text { Turan } \\
\end{array}$ & & & & & & & & & \\
\hline $\begin{array}{l}\begin{array}{l}\text { Paft./A/930 Pars. } \\
\text { clay) }\end{array} \\
\end{array}$ & 172 & 1.50 & 86 & $\begin{array}{c}18.9 \\
\gamma_{0}=16\end{array}$ & 896 & 390 & 157 & 173 & 180 \\
\hline \begin{tabular}{|l}
544 Ayhan Dede G22B/ \\
$574 / 11$ (weathered diorite) \\
\end{tabular} & 190 & 1.50 & 95 & $\begin{array}{c}18.0 \\
\gamma_{0}=16\end{array}$ & 1020 & 453 & 172 & 204 & 208 \\
\hline \begin{tabular}{|l|}
502 Ebru Çınar $30 \mathrm{~L} 1 \mathrm{C} /$ \\
$440 / 8$ (clay stone)
\end{tabular} & 147 & 1.00 & 140 & $\begin{array}{c}22.7 \\
\gamma_{0}=20\end{array}$ & 1210 & 489 & 248 & 274 & 280 \\
\hline
\end{tabular}

(1) $\mathrm{q}_{\mathrm{u}}=$ unconfined compressive strength; (2) Terzaghi and Peck (1976); (3) $\mathrm{q}_{\mathrm{a}}=0.025 \gamma_{\mathrm{p}} \mathrm{V}_{\mathrm{s}}$ (Eq.7), $\mathrm{n}=4$. 
Table 3 Results of numerical example $\left(H=15 \mathrm{~m}, \mathrm{~V}_{\mathrm{p} 2}=700 \mathrm{~m} / \mathrm{sec}, \mathrm{V}_{\mathrm{s} 2}=200 \mathrm{~m} / \mathrm{sec}, \mathrm{c}=52 \mathrm{kPa}, \phi=0\right),\left(\mathrm{V}_{\mathrm{p} 1}=700 \mathrm{~m} / \mathrm{sec}\right.$ above the base).

\begin{tabular}{|c|c|c|c|c|}
\hline Formula & Equation & Numerical calculations & Result & Unit \\
\hline$\gamma_{\mathrm{p}}=\gamma_{0}+0.002 \mathrm{~V}_{\mathrm{p} 1}$ & eqn $(8 \mathrm{a})$ & $\gamma_{\mathrm{p}}=16+0.002(700)$ & $17.4^{(1)}$ & $\mathrm{kN} / \mathrm{m}^{3}$ \\
Laboratory & - & - & 4 & $\mathrm{kN} / \mathrm{m}^{3}$ \\
\hline $\mathrm{n}=4$ & Table 1 & $\mathrm{~V}_{\mathrm{s} 2} \leq 750 \mathrm{~m} / \mathrm{sec}$ & - \\
$\mathrm{q}_{\mathrm{f}}=\mathrm{c} \mathrm{N}_{\mathrm{c}}+\gamma \mathrm{D}_{\mathrm{f}} \mathrm{N}_{\mathrm{q}}$ & eqn $(26)$ & $\mathrm{q}_{\mathrm{f}}=52(5.14)+17.2(2.9) 1$ & 318 & $\mathrm{kN} / \mathrm{m}^{2}$ \\
$\mathrm{q}_{\mathrm{f}}=0.1 \gamma \mathrm{V}_{\mathrm{s} 2}$ & eqn (7) & $\mathrm{q}_{\mathrm{f}}=0.1(17.4) 200$ & 348 & $\mathrm{kN} / \mathrm{m}^{2}$ \\
$\mathrm{q}_{\mathrm{a}}=\mathrm{q}_{\mathrm{f}} / \mathrm{n}$ & eqn (3) & $\mathrm{q}_{\mathrm{a}}=348 / 4$ & 87 & $\mathrm{kN} / \mathrm{m}^{2}$ \\
\hline $\mathrm{k}_{\mathrm{s}}=40 \mathrm{q}_{\mathrm{a}}=4 \gamma \mathrm{V}_{\mathrm{s} 2} / \mathrm{n}$ & eqn (12) & $\mathrm{k}_{\mathrm{s}}=40(87)$ & 3480 & $\mathrm{kN} / \mathrm{m}^{3}$ \\
$\mathrm{G}=\gamma \mathrm{V}_{\mathrm{s}}^{2} / \mathrm{g}$ & eqn (14) & $\mathrm{G}=17.4(200)^{2} / 9.81$ & 70948 & $\mathrm{kN} / \mathrm{m}^{2}$ \\
\hline$\alpha=\left(\mathrm{V}_{\mathrm{p} 2} / \mathrm{V}_{\mathrm{s} 2}\right)^{2}$ & eqn (18) & $\alpha=(700 / 200)^{2}$ & 12.25 & - \\
$\mu=(\alpha-2) / 2(\alpha-1)$ & eqn $(19)$ & $\mu=(12.25-2) / 2(11.25)$ & 0.456 & - \\
$\mathrm{E}=2(1+\mu) \mathrm{G}$ & eqn $(17)$ & $\mathrm{E}=2(1.456) 70948$ & 206537 & $\mathrm{kN} / \mathrm{m}^{2}$ \\
\hline $\mathrm{E}_{\mathrm{c}}=\gamma \mathrm{V}_{\mathrm{P} 2}^{2} / \mathrm{g}$ & eqn $(15)$ & $17.4(700)^{2} / 9.81$ & 870000 & $\mathrm{kN} / \mathrm{m}^{2}$ \\
$\mathrm{E}_{\mathrm{k}}=\mathrm{E} / 3(1-2 \mu)$ & eqn $(24)$ & $206537 / 3(1-2 \mu)$ & 774417 & $\mathrm{kN} / \mathrm{m}^{2}$ \\
$\mathrm{E}_{\mathrm{k}}=\mathrm{E}(\alpha-1) / 3$ & eqn $(25)$ & $206537(12.25-1) / 3$ & 774514 & $\mathrm{kN} / \mathrm{m}^{2}$ \\
\hline $\mathrm{d}=$ displacement & eqn $(11)$ & $\mathrm{d}=\mathrm{q}_{\mathrm{a}} / \mathrm{k}_{\mathrm{s}}=87 / 3480$ & 0.025 & $\mathrm{~m}$ \\
\hline
\end{tabular}

(1) Result of Eq. (8a), $\gamma=17.4 \mathrm{kN} / \mathrm{m}^{3}$ is used in all subsequent expressions.

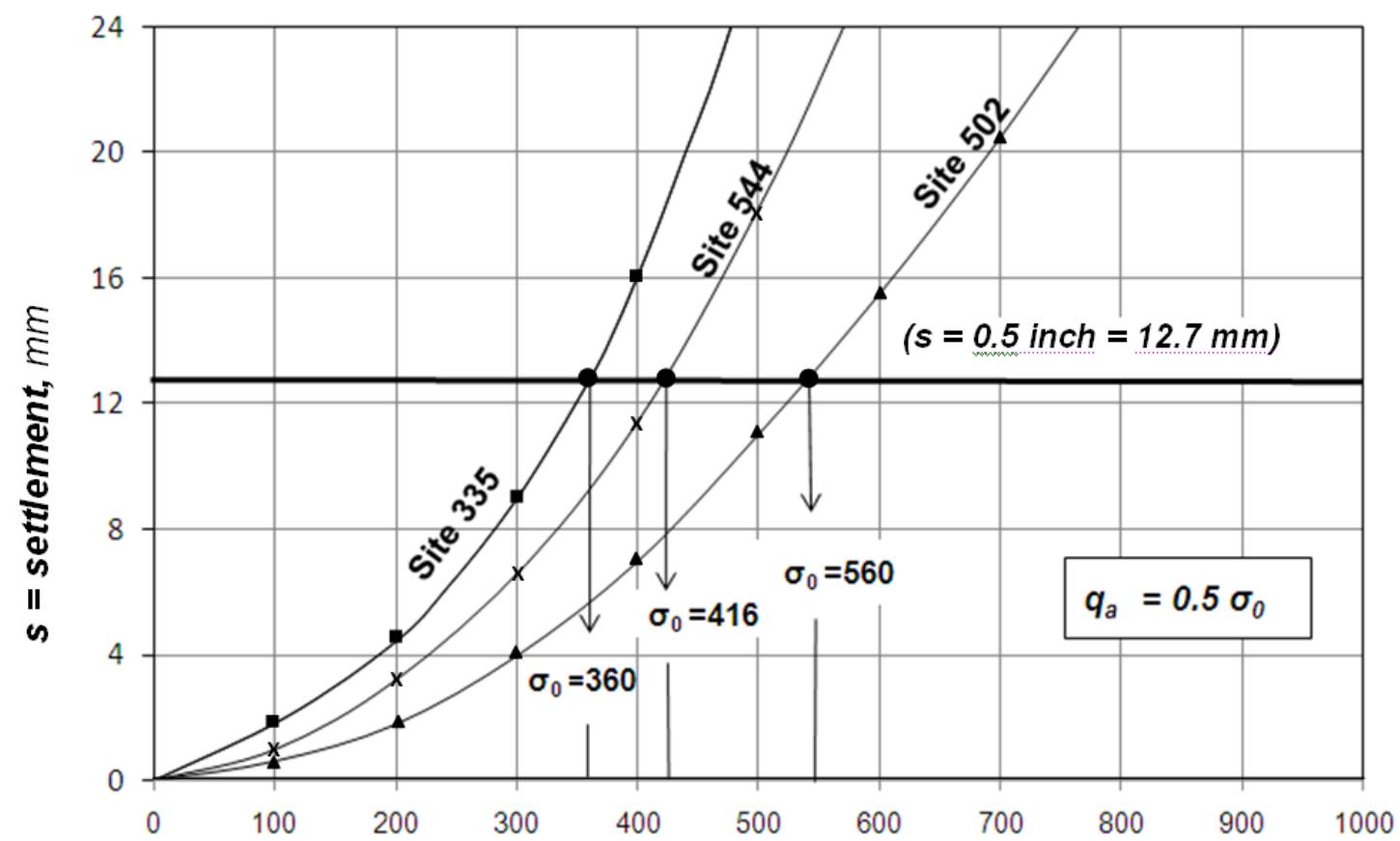

Fig. 4 Load test results at Sites No: 335, 502, and 544 ( $\sigma=$ pressure under the test plate, $\mathrm{kPa} ; \sigma_{0}=2$, $\mathrm{q}_{\mathrm{a}}=$ pressure, which produces $\mathrm{s}=12.7 \mathrm{~mm}$ ).

proposed "dynamic" method using $P$ and $S$ - wave velocities are in very close agreement with those of the plate load testing. The allowable bearing pressures $q_{a}$, in accordance with the conventional theory assuming $\mathrm{N}_{\mathrm{c}}=5.14$ and $\mathrm{N}_{\mathrm{q}}=1$, are also calculated using

$$
\mathrm{q}_{\mathrm{a}}=\left(\mathrm{cN}_{\mathrm{c}}+\gamma \mathrm{D}_{\mathrm{f}} \mathrm{N}_{\mathrm{q}}\right) / 3.0
$$

\section{Numerical Example}

For purposes of illustration, a soft clayey soil layer of $\mathrm{H}=15 \mathrm{~m}$ beneath a shallow strip footing of depth $\mathrm{D}_{\mathrm{f}}=2.90 \mathrm{~m}$, width $\mathrm{B}=1.30 \mathrm{~m}$, is considered. The in situ measured seismic wave velocities are determined to be $\mathrm{V}_{\mathrm{p} 2}=700 \mathrm{~m} / \mathrm{sec}$ and $\mathrm{V}_{\mathrm{s} 2}=200 \mathrm{~m} / \mathrm{sec}$, within the 
soil layer just below the foundation base. By coincidence, the $P$ - wave velocity within the soil layer above the foundation base is also measured to be $\mathrm{V}_{\mathrm{p} 1}=700 \mathrm{~m} / \mathrm{sec}$. A comprehensive set of classical soil investigations, including a number of bore hole data and laboratory testing exist for this particular site, together with the numerical values of various soil parameters ( $\mathrm{c}=52 \mathrm{kPa}$, and $\phi=0)$, including the bearing pressure capacity determined to be $\mathrm{q}_{\mathrm{f}}=322$ $\mathrm{kPa}$ by the conventional method of Terzaghi and Peck [30]. Therefore, the validity and the reliability of the proposed empirical formulae have been rigorously verified. Calculation of some elasticity parameters, using the empirical expressions presented herein, is summarised in Table 3.

\section{Discussion on the Degrees of Accuracy}

The degrees of accuracy of the proposed "dynamic" method are quite satisfactory and consistent as attested rigorously at more than 550 construction sites. The conventional approach however, depends heavily on the degrees of accuracy of in situ and laboratory determined soil parameters. In fact, the allowable bearing pressure calculations are very sensitive to the values of $c$, and $\phi$, determined in the laboratory using so-called "undisturbed" soil samples, which may not necessarily represent the true in situ conditions. This may explain the reason why at a number of construction sites, some inconsistent and erratic results for $q_{a}$ are obtained using the classical theory, as already depicted in Fig. 2, because the laboratory measured $c$, and $\phi$ - values differed considerably from one soil sample into the other. The "Point Load" tests (Fig. 4) of rock samples have been carried out for $V_{s 2}$ values greater than $400 \mathrm{~m} / \mathrm{sec}$ as recommended by Hunt [31].

\section{Conclusions}

The $P$ and $S$ - wave velocities are most powerfull soil properties representing a family of geotechnical soil parameters, ranging from compressive and shear strengths to void ratio, from subgrade coefficient to cohesion etc,

Once the shear and $P$ - wave velocities are measured, the allowable bearing pressure, the coefficient of subgrade reaction, various other elasticity parameters, as well as the approximate values of the unit weight are rapidly and economically determined, using relatively simple empirical expressions. Bore hole drilling and laboratory testing of soil samples including the "point load" method of rock samples, may be beneficially utilised for correlation purposes.

\section{Acknowledgements}

The writers gratefully acknowledge the supply of voluminous site data by Mr. Mustafa Cevher, Head, the Earthquake Research Department, Greater Municipality of Kocaeli Province, and also the scientific assistance by Dr. Osman Uyanık, Assoc. Professor of Geophysics at Suleyman Demirel University, Turkey.

\section{References}

[1] W. E. Schulze, Grundbau, in: B. G. Taubner, Deutsche Forschungsgesellschaft für Bodenmechanik (7th ed.), Leipzig, Germany, also available: Technical University of Istanbul, Issue 48, No DK624-15, Uçler Printing House, Istanbul, Turkiye, 1943.

[2] D. F. Coates, Rock Mechanics Principles, Mines Branch Monographs, No. 874, 1970.

[3] B. O. Hardin, and W. L. Black, Vibration modulus of normally consolidated clays, Journal of the Soil Mechanics and Foundation Division 94 (SM2) (1968) 353-369.

[4] B. O. Hardin and V. P. Drnevich, Shear modulus and damping in soils, Journal of the Soil Mechanics and Foundation Division 98 (SM7) (1972) 667-692.

[5] T. Ohkubo and A. Terasaki, Physical Property and Seismic Wave Velocity of Rocks, OYO Corporation, Japan, 1976.

[6] T. Imai and M. Yoshimura, The Relation of Mechanical Properties of Soils to P and S- Wave Velocities for Soil Ground in Japan, Urana Research Institue, OYO Corporation, 1976.

[7] R. H. Tatham, Vp/Vs and lithology, Geophysics 47 (1982) 336-344. 
[8] R. Willkens, G. Simmons and L. Caruso, The Ration $\mathrm{Vp} / \mathrm{Vs}$ as a discriminant of composition for siliceous limestones, Geophysics 49 (11) (1984) 1850-1860.

[9] D. E. Phillips, D. H. Han and M. D. Zoback, Empirical relationships among seismic velocity, effective pressure, porosity, and clay content in sandstone, Geophysics, 54 (1) (1989) 82-89.

[10] A. D. Keceli, Determination of bearing capacity of soils by means of seismic methods (in Turkish), Geophysical Journal 4 (1990) 83-92.

[11] A. D. Keceli, Bearing capacity determination by seismic methods, Geophysical Journal, 14, No. 1-2, 2000 (in Turkish).

[12] D. Jongmans, The application of seismic methods for dynamic characterization of soils, Bulletin of International Association of Engineering Geology. 46 (1992) 63-69.

[13] J. P. Sully and R. G. Campanella, Evaluation of in situ anisotropy from crosshole and downhole shear wave velocities measurements, Geotechnique 45 (2) (1995) 267-282.

[14] L. J. Pyrak-Nolte, S. Roy and B. 1. Mullenbach, Interface waves propagated along a fracture, Journal of Applied Geophysics 35 (1996) 79-87.

[15] R. G. Campanella and W. P. Stewart, Seismic cone analysis using digital signal processing for dynamic site characterization, Canadian Geotechnical Journal 29 (3) (1992) 477-486.

[16] A. P. Butcher and J. J. Powell, Practical considerations for field geophysical techniques to used assess ground stiffness, in: Proc. Int. Conf. on Advances in Site Investigation Practice, ICE London, March 1995, Thomas Telford, pp. 701-714.

[17] M. M. Abd El-Rahman, I. Setto and A. El-Werr, Inferring mechanical properties of the foundation material, from geophysical measurements, Egyptian Geophysical Society, in: Proceedings of the 9th Annual Meeting, 1992, pp. 206-228.

[18] IRTP, ISSMGE Technical Committee TC16, Ground Property Characterization from In-situ Testing, International Reference Test Procedure (IRTP) for the Cone Penetration Test (CPT) and the Cone Penetration Test with pore pressure (CPTU), in: Proc. XIIth ECSMGE Amsterdam, Balkema, 1999, pp. 2195-2222.

[19] J. G. Sieffert and Ch. Bay-Gress, Comparison of the European bearing capacity calculation methods for shallow foundations, Geotechnical Engineering 143 (2000) 65-74.
[20] E. Turker, Computation of ground bearing capacity from shear wave velocity, in: D. Bergman et al. (Eds.), Continuum Models and Discrete Systems, Netherlands, 2004, pp. 173-180.

[21] S. S. Tezcan, Z. Ozdemir and A. D. Keceli, Allowable bearing capacity of shallow foundations based on shear wave velocity, Journal of Geotechnical and Geological Engineering 24 (2006) 203-218.

[22] K. R. Massarsch, Deformation properties of fine-grained soils from seismic tests, in: International Conference on Site Characterization, ISC'2, 19-22 Sept. Porto, 2004, pp. 133-146.

[23] K. H. Stokoe and R. D. Woods, Insitu shear wave velocity by cross-hole method, Journal of the Soil Mechanics and Foundation Divison 98 (SM5) (1972) 443-460.

[24] S. S. Tezcan, S. M. Erden and H. T. Durgunoğlu, Insitu measurement of shear wave velocity at Boğaziçi University Campus, in: Proc. of the International Conference on Soil Mechanics and Foundation Engineering, Vol. 2, April 1975, pp. 157-164.

[25] A. P. Butcher, R. G. Campanella, A. M. Kaynia and K. R. Massarsch, Seismic cone downhole procedure to measure shear wave velocity: A guideline prepared by ISSMGE TC10: Geophysical Testing in Geotechnical Engineering, in: Proc. of the XVIth International Conference on Soil Mechanics and Geotechnical Engineering, 5p., Osaka, Japan, May 2006.

[26] F. E. Richart, J. R. Hall and R. D. Woofs, Vibrations of Soils and Foundations, Prentice Hall, Inc, Englewood Cliffs, N.J., 1970.

[27] L. K. Kramer, Geotechnical Earthquake Engineering, Prentice Hall international Series in Civil Engineering Mechanics, Upper Saddle River, N.J., USA, 1996.

[28] J. C. Santamarina, A. K. Klein and M. A. Fam, Soils and Waves, John Wiley \& Sons, New York, N.Y., USA, 2001.

[29] A. D. Keceli, Applied Geophysics, UCTEA Chamber of Geophysical Engineers, Ankara, Turkey, July 2009, http: //jeofizik.org.tr (in Turkish).

[30] K. Terzaghi and R. B. Peck, Soil Mechanics in Engineering Practice (2nd ed.), John Wiley \& Sons, London, 1976.

[31] R. E. Hunt, Geotechnical Engineering Investigation Manual, Mc Graw Hill Book Co., New York, N.Y., 1984.

[32] Z. T. Bieniawski, Engineering Rock Mass Classification, Wiley - Interscience Publication, New York, NY, John Wiley \& Sons, USA, 1979. 